\title{
FAKTOR - FAKTOR YANG BERHUBUNGAN DENGAN KEPUASAN PESERTA BADAN PENYELENGGARA JAMINAN SOSIAL (BPJS) TERHADAP PELAYANAN PROGRAM BPJS KESEHATAN
}

\author{
Fajar Ardianing Gofur*, Cucu Herawati**
}

\begin{abstract}
ABSTRAK
Berdasarkan hasil laporan Indeks Kepuasan Msyarakat (IKM) tahun 2013 di UPTD Puskesmas Astanagarib Kota Cirebon, dilaporkan bahwa Puskesmas Astanagarib berada di peringkat 4 terbawah dengan persentase tingkat kepuasan secara keseluruhan 73,54\% dengan jumlah peserta Badan Penyelenggara Jaminan Sosial (BPJS) selama 5 bulan terakhir sebanyak 2.577 peserta dari 5.983 penduduk, rendahnya persentase dalam IKM dan jumlah peserta BPJS tersebut dipengaruhi oleh berbagai macam faktor seperti kemudahan dalam prosedur pelayanan, informasi, ketepatan waktu pelayanan, kehandalan, kecepatan dalam pelayanan, kenyamanan lingkungan, serta kesopanan dan keramahan. Tujuan penelitian ini adalah untuk mengetahui hubungan antara faktor-fakto yang berhubungan dengan kepuasan peserta Badan Penyelenggara Jaminan Sosial (BPJS) terhadap pelayanan program Badan Penyelenggara Jaminan Sosial (BPJS) Kesehatan di UPTD Puskesmas Astanagarib Kota Cirebon tahun 2014. Jenis penelitian deskriptif analitik dengan desain studi Cross Sectional. Populasi dalam penelitian ini adalah seluruh peserta BPJS di Kelurahan Pekalipan (wilayah kerja UPTD Puskesmas Astanagarib) Kota Cirebon tahun 2014 sebanyak 2.577 peserta. Jumlah sampel sebanyak 97 peserta yang diambil secara Accidental Sampling. Data dianalisis secara statistik menggunakan uji Chi Square pada tingkat kemaknaan 5\% $(0,05)$. Hasil penelitian ini menunjukkan ada hubungan yang bermakna antara ketepatan waktu dengan kepuasan pelayanan program BPJS Kesehatan $(\mathrm{p}=0,00)$, ada hubungan yang bermakna antara informasi dengan kepuasan pelayanan program BPJS Kesehatan $(\mathrm{p}=0,00)$, ada hubungan yang bermakna antara kompetensi teknis dengan dengan kepuasan pelayanan program BPJS Kesehatan $(\mathrm{p}=0,00)$ dan tidak ada hubungan yang bermakna antara hubungan antar manusia dengan dengan kepuasan pelayanan program BPJS Kesehatan $(\mathrm{p}=$ $0,39)$.
\end{abstract}

Kata Kunci : Tingkat Kepuasan, peserta BPJS

\section{ABSTRACT}

Based on report result of Indeks Kepuasan Masyarakat (IKM) 2013 in UPTD local government clinic of Astanagrip Cirebon, reviewed that Astanagrip local government clinic was in bottom 4 through overall of satisfaction percentage is $73,54 \%$ with participants of Badan Penyelenggara Jaminan Sosial (BPJS) as long as 5 months are 2.577 of 5.983 inhabitants, the low of percentage on IKM and the number of BPJS participants is influenced on kind of factors like easy of service procedure, information, punctuality of service, professionalism, speed, comfortable, polite behavior and friendly. Aim of this research is to know the relation of that related factors with Badan Penyelenggara Jaminan Sosial (BPJS) participants satisfaction on Badan Penyelenggara Jaminan Sosial (BPJS) Kesehatan program service in UPTD local government clinic of Astanagrip Cirebon 2014. Analytical Descriptive research with Cross Sectional design. Population in this research is all of district Pekalipan (UPTD local government clinic work area) Cirebon BPJS participants 2014 are 2.577 participants. The writer has taken 97 participants by Accidental Sampling for the sample of research. The data was analyzed by statistical accounting used Chi Square test on sense level 5\% (0, 05). Result of this research shows that there was a means relation between punctuality of service with BPJS Kesehatan program service satisfaction $(\mathrm{p}=0,00)$, information with BPJS Kesehatan program service satisfaction $(\mathrm{p}=0,00)$, technical competence with BPJS Kesehatan program service satisfaction $(\mathrm{p}=0,00)$, and there wasn't a means relation between people relation with BPJS Kesehatan program service satisfaction $(\mathrm{p}=0,39)$.

Key Words : Level of Satisfaction, participants BPJS

\footnotetext{
* Alumni PSKM STIKes Cirebon Lulus Tahun 2014

** Staf Pengajar Program Studi S1 Kesehatan Masyarakat STIKes Cirebon
} 


\section{LATAR BELAKANG}

Pelayanan kesehatan salah satu kebutuhan dasar yang diperlukan semua orang. secara umum kebutuhan pelayanan kesehatan yang bermutu adalah pelayanan kesehatan yang dapat memberikan kepuasan kepada para pengguna jasa pelayanan kesehatan yang bermutu menunjukan tingkat kesempurnaan dalam memenuhi kebutuhan dan tuntutan setiap pasien. ${ }^{1}$

Sesuai dengan Undang-Undang no. 24 tahun 2011 tentang Badan Penyelenggara Jaminan Sosial (BPJS) pemerntah Indonesia membentuk program Jaminan Kesehatan Nasional (JKN) yang dikelola oleh Badan Penyelenggara Jaminan Sosial (BPJS) Kesehatan untuk menjangkau pelayanan kesehatan yang bermutu, adil, merata, serta memiliki derajat kesehatan yang setinggitingginya. $^{2}$

Puskesmas adalah suatu instansi kesehatan yang bergerak dalam bidang pelayanan jasa yaitu pelayanan medis. Puskesmas memegang peranan penting dalam pemberian pelayanan kesehatan masyarakat. Berdasarkan laporan UPTD Puskesmas Astanagarib tahun 2014, jumlah penduduk 5.983 jiwa dan terdapat $1.938 \mathrm{KK}$, sedangkan yang sudah terdaftar di BPJS hanya sebanyak 2.577 jiwa yang terdiri dari 2.234 peserta PBI (Penerima Biaya Iuran) dan 343 peserta non PBI. ${ }^{3}$

Menurut hasil laporan Indeks Kepuasan Masyarakat (IKM) UPTD Puskesmas Astanagarib tahun 2012 didapati gambaran kepuasan masyarakat dalam aspek kemudahan dalam prosedur pelayanan $86,0 \%$, informasi $96,7 \%$, ketepatan waktu pelayanan 53,3\%, kehandalan $100 \%$, kecepatan dalam pelayanan 53,3\%, kenyamanan lingkungan 96,7\%, kesopanan dan keramahan $100 \%$. Tingkat kepuasan secara keseluruhan 73,54\%.4 Jumlah kunjungan yang menggunakan kartu BPJS di UPTD Puskesmas Astanagarib tahun 2014. ${ }^{4}$

Tabel 1 Jumlah Kunjungan Pengguna Kartu BPJS

\begin{tabular}{lccccc}
\hline Bulan & Januari & Februari & Maret & April & Mei \\
\hline Jumlah Kunjungan & 634 & 806 & 815 & 692 & 622 \\
\hline
\end{tabular}

Berdasarkan hasil kajian di atas diperlukan suatu penelitian lanjutan mengenai faktor-faktor apa saja yang berhubungan dengan kepuasan peserta BPJS terhadap pelayanan program Badan Penyelenggara Jaminan Sosial (BPJS) di UPTD Puskesmas Astanagarib Kota Cirebon. Tujuan dalam penelitian ini untuk mengetahui faktor-faktor yang berhubungan dengan tingkat kepuasan peserta BPJS terhadap pelayanan BPJS Kesehatan di UPTD Puskesmas Astanagarib Kota Cirebon tahun 2014.

\section{METODE PENELITIAN}

Dalam penelitian ini penulis menggunakan jenis rancangan deskriptif analitik dengan pendekatan Cross Sectiona. yaitu rancangan penelitian dengan melakukan pengukuran atau pengamatan pada saat bersamaan (sekali waktu) antara faktor risiko/paparan dengan penyakit. ${ }^{5}$ Populasi dalam penelitian ini adalah seluruh pasien pemegang kartu BPJS Kesehatan bulan Januari hingga Mei 2014 yang berobat di UPTD Puskesmas Astanagarib Kota Cirebon sejumlah 2.577 peserta dengan rata-rata 18 peserta perhari. Besarnya sampel dalam penelitian ini di tentukan sebanyak 97 peserta dari 2.577 peserta BPJS hingga bulan Mei 2014 yang berada di wilayah kerja UPTD Puskesmas Astanagarib Kota Cirebon. Pengambilan sampel tersebut dilakukan dengan metode Quota Sampling, yaitu pengambilan sampel dilakukan dengan cara menetapkan sejumlah anggota sampel secara quotum atau jatah. ${ }^{6}$ 
HASIL PENELITIAN

Hubungan antara aspek ketepatan waktu dengan kepuasan pelayanan program BPJS Kesehatan.

Tabel 2 Hubungan Antara Aspek Ketepatan Waktu Dengan Kepuasan Pelayanan Program BPJS Kesehatan.

\begin{tabular}{|c|c|c|c|c|c|c|c|}
\hline \multirow{2}{*}{$\begin{array}{l}\text { Ketepatan } \\
\text { Waktu }\end{array}$} & \multicolumn{4}{|c|}{ Kepuasan } & \multicolumn{2}{|c|}{ Total } & \multirow[t]{2}{*}{ P.value } \\
\hline & \multicolumn{2}{|c|}{ Kurang Puas } & \multicolumn{2}{|c|}{ Puas } & & & \\
\hline Kurang Tepat & 35 & 71,4 & 14 & 28,6 & 49 & 100 & \\
\hline Tepat & 14 & 29,2 & 34 & 70,8 & 48 & 100 & 0,00 \\
\hline Total & 49 & 50,5 & 48 & 49,5 & 97 & 100 & \\
\hline
\end{tabular}

Berdasarkan tabel 2 didapatkan bahwa peserta BPJS di UPTD Puskesmas Astanagarib Kota Cirebon tahun 2014 yang menyatakan kurang puas tentang ketepatan waktu lebih dari setengahnya menyatakan kurang tepat terhadap pelayanan program BPJS yaitu sebanyak 35 peserta $(71,4 \%)$, dan peserta BPJS yang menyatakan puas tentang ketepatan waktu lebih dari setengahnya menyatakan tepat juga terhadap pelayanan program BPJS yaitu sebanyak 34 peserta $(70,8 \%)$. Dari hasil statistik diperoleh $\mathrm{P}=0,00(\mathrm{p} \leq 0,05)$ yang menunjukan $\mathrm{Ha}=$ diterima, artinya ada hubungan antara tingkat ketepatan waktu terhadap kepuasan dalam pelayanan program BPJS Kesehatan di UPTD Puskesmas Astanagarib Kota Cirebon tahun 2014.

Hubungan antara aspek informasi dengan kepuasan pelayanan program BPJS Kesehatan.

Tabel 3 Hubungan Antara Aspek Informasi Dengan Kepuasan PelayananProgram BPJS Kesehatan.

\begin{tabular}{|c|c|c|c|c|c|c|c|}
\hline \multirow[t]{3}{*}{ Informasi } & \multicolumn{4}{|c|}{ Kepuasan } & \multicolumn{2}{|c|}{ Total } & \multirow[t]{2}{*}{ Pvalue } \\
\hline & $\mathrm{Ku}$ & uas & & & & & \\
\hline & $\mathrm{n}$ & $\%$ & $\mathrm{n}$ & $\%$ & $\mathrm{n}$ & $\%$ & \\
\hline Kurang Jelas & 34 & 87,2 & 5 & 12,8 & 39 & 100 & \\
\hline Jelas & 15 & 25,9 & 43 & 74,1 & 58 & 100 & 0,00 \\
\hline Total & 49 & 50,5 & 48 & 49,5 & 97 & 100 & \\
\hline
\end{tabular}

Berdasarkan tabel 3 didapatkan bahwa peserta BPJS di UPTD Puskesmas Astanagarib Kota Cirebon tahun 2014 yang menyatakan kurang puas tentang informasi sebagian besar menyatakan kurang jelas terhadap informasi pelayanan program BPJS yaitu sebanyak 34 peserta $(87,2 \%)$, dan peserta BPJS yang menyatakan puas tentang informasi lebih dari setengahnya menyatakan jelas juga terhadap informasi pelayanan program BPJS yaitu sebanyak 43 peserta $(74,1 \%)$.

Dari hasil statistik diperoleh $\mathrm{P}=0,00(\mathrm{p} \leq 0,05)$ yang menunjukan $\mathrm{Ha}=$ diterima, artinya ada hubungan antara tingkat informasi dengan kepuasan terhadap pelayanan program BPJ Kesehatan di UPTD Puskesmas Astanagarib Kota Cirebon tahun 2014. 


\section{Hubungan antara aspek kompetensi teknis dengan kepuasan pelayanan program BPJS Kesehatan.}

Tabel 4 Hubungan Antara Aspek Kompetensi Teknis Dengan Kepuasan Pelayanan Program BPJS Kesehatan.

\begin{tabular}{|c|c|c|c|c|c|c|c|}
\hline \multirow[t]{3}{*}{ Kompetensi Teknis } & \multicolumn{4}{|c|}{ Kepuasan } & \multirow{2}{*}{\multicolumn{2}{|c|}{ Total }} & \multirow[t]{3}{*}{ P.Value } \\
\hline & \multicolumn{2}{|c|}{ Kurang Puas } & \multicolumn{2}{|c|}{ Puas } & & & \\
\hline & $\mathrm{n}$ & $\%$ & $\mathrm{n}$ & $\%$ & $\mathrm{n}$ & $\%$ & \\
\hline Kurang Baik & 34 & 77,3 & 10 & 22,7 & 44 & 100 & \\
\hline Baik & 15 & 28,3 & 38 & 71,7 & 53 & 100 & 0,00 \\
\hline Total & 49 & 50,5 & 48 & 49,5 & 97 & 100 & \\
\hline
\end{tabular}

Berdasarkan tabel 4 didapatkan bahwa peserta BPJS di UPTD Puskesmas Astanagarib Kota Cirebon tahun 2014 yang menyatakan kurang puas tentang kompetensi teknis sebagian besar menyatakan kurang baik terhadap pelayanan program BPJS yaitu sebanyak 34 peserta $(77,3 \%)$, dan peserta BPJS yang menyatakan puas tentang kompetensi teknis lebih dari setengahnya menyatakan baik juga terhadap pelayanan program BPJS yaitu sebanyak 38 peserta $(71,7 \%)$.

Dari hasil statistik diperoleh $\mathrm{P}=0,00(\mathrm{p} \leq 0,05)$ yang menunjukan $\mathrm{Ha}=$ diterima, artinya ada hubungan antara tingkat kompetensi teknis terhadap kepuasan dalam pelayanan program BPJS Kesehatan di UPTD Puskesmas Astanagarib Kota Cirebon tahun 2014.

Hubungan antara aspek hubungan antar manusia dengan kepuasan pelayanan program BPJS Kesehatan.

Tabel 5 Hubungan Antara Aspek Hubungan Antar ManusiaDengan Kepuasan Pelayanan Program BPJS Kesehatan.

\begin{tabular}{lcccccccc}
\hline \multirow{2}{*}{$\begin{array}{c}\text { HubunganAntar } \\
\text { Manusia }\end{array}$} & \multicolumn{4}{c}{ Kepuasan } & \multicolumn{2}{c}{ Total } & \multirow{2}{*}{ P value } \\
\cline { 2 - 7 } & \multicolumn{2}{c}{ Kurang Puas } & \multicolumn{2}{c}{ Puas } & & & \\
\cline { 2 - 7 } & $\mathrm{n}$ & $\%$ & $\mathrm{n}$ & $\%$ & $\mathrm{n}$ & $\%$ & \\
\hline Kurang Baik & 16 & 59,3 & 11 & 40,7 & 27 & 100 & 0,39 \\
\hline Baik & 33 & 47,1 & 37 & 52,9 & 70 & 100 & \\
\hline Total & 49 & 50,5 & 48 & 49,5 & 97 & 100 & \\
\hline
\end{tabular}

Berdasarkan tabel 5 didapatkan bahwa peserta BPJS di UPTD Puskesmas Astanagarib Kota Cirebon tahun 2014 yang menyatakan kurang puas tentang hubungan antar manusia lebih dari setengahnya menyatakan kurang baik terhadap pelayanan program BPJS yaitu sebanyak 16 peserta $(59,3 \%)$, dan peserta BPJS yang menyatakan puas tentang hubungan antar manusia lebih dari setengahnya menyatakan baik juga terhadap pelayanan program BPJS yaitu sebanyak 37 peserta $(52,9 \%)$.

Dari hasil statistik diperoleh $\mathrm{P}=0,39(\mathrm{p}>0,05)$ yang menunjukan $\mathrm{Ha}=$ ditolak, artinya tidak ada hubungan antara tingkat hubungan antar manusia terhadap kepuasan dalam pelayanan program BPJS Kesehatan di UPTD Puskesmas Astanagarib Kota Cirebon tahun 2014.

\section{PEMBAHASAN}

Hubungan Antara Aspek Ketepatan Waktu Terhadap Kepuasan Pelayanan Program BPJS Kesehatan

Hasil uji statistik diperoleh $\mathrm{P}=0,00(\mathrm{p} \leq 0,05)$ yang menunjukan $\mathrm{Ha}=$ diterima, artinya ada 
hubungan antara tingkat ketepatan waktu terhadap kepuasan dalam pelayanan program BPJS Kesehatan di UPTD Puskesmas Astanagarib Kota Cirebon tahun 2014. Agar berhasil pelayanan kesehatan itu harus dilaksanakan dalam waktu dan cara yang tepat oleh pemberi pelayanan yang tepat dan menggunakan peralatan dan obat yang tepat serta dengan biaya yang efisien. Faktor ketepatan ini meliputi akses, waktu tunggu dan tindakan. ${ }^{6}$ Asumsi peneliti mengenai hal tersebut yaitu dikarenakan masih adanya keterlambatan terhadap waktu tindakan, dan terkadang masih terjadi penumpukan antrian dikarenakan terbatasnya petugas kesehatan di UPTD Puskesmas Astanagarib Kota Cirebon.

\section{Hubungan Antara Aspek Informasi Terhadap Kepuasan Pelayanan Program BPJS Kesehatan}

Dari hasil statistik diperoleh $\mathrm{P}=0,00(\mathrm{p} \leq 0,05)$ yang menunjukan $\mathrm{Ha}=$ diterima, artinya ada hubungan antara tingkat informasi terhadap kepuasan dalam pelayanan program BPJS Kesehatan di UPTD Puskesmas Astanagarib Kota Cirebon tahun 2014.

Pelayanan kesehatan yang bermutu harus mampu memberikan informasi yang jelas tentang apa, siapa, kapan, di mana dan bagaimana pelayanan kesehatan itu dilaksanakan. Aspek informasi ini sangat penting pada tingkat Puskesmas. ${ }^{6}$ Asumsi peneliti mengenai hal tersebut yaitu dikarenakan masih adanya para kader dan tokoh masyarakat yang belum bisa menyampaikan informasi secara menyeluruh kepada masyarakat sekitar tentang informasi prosedur pelayanan program BPJS Kesehatan, informasi mengenai jenis pelayanan yang dijamin dan tidak dijamin oleh BPJS Kesehatan, serta informasi mengenai manfaat (benefit) program BPJS Kesehatan.

\section{Hubungan Antara Aspek Kompetensi Teknis Terhadap Kepuasan Pelayanan Program BPJS Kesehatan}

Dari hasil statistik diperoleh $\mathrm{P}=0,00(\mathrm{p} \leq 0,05)$ yang menunjukan $\mathrm{Ha}=$ diterima, artinya ada hubungan antara tingkat kompetensi teknis terhadap kepuasan dalam pelayanan program BPJS Kesehatan di UPTD Puskesmas Astanagarib Kota Cirebon tahun 2014. Kompetensi teknis berhubungan dengan bagaimana pemberi pelayanan kesehatan mengikuti standard pelayanan kesehatan yang disepakati, antara lain meliputi kepatuhann ketepatan, kebenaran dan konsistensi. ${ }^{6}$ Tidak terpenuhinya kompetensi teknis dapat mengakibatkan berbagai hal, mulai dari penyimpangan kecil terhadap standard pelayanan kesehatan, sampai pada kesalahan fatal sehingga menurunkan mutu pelayanan kesehatan dan membahayakan jiwa pasien. ${ }^{2}$

Asumsi peneliti mengenai hal tersebut dikarenakan masih adanya kekurangan dalam sarana prasarana pendukung dan kesigapan beberapa petugas kesehatan terhadap pelayanan program BPJS Kesehatan.

\section{Hubungan Antara Aspek Hubungan Antar Manusia Terhadap Kepuasan Pelayanan Program BPJS Kesehatan}

Dari hasil statistik diperoleh $\mathrm{P}=0,39(\mathrm{p}>0,05)$ yang menunjukan $\mathrm{Ha}=$ ditolak, artinya tidak ada hubungan antara tingkat hubungan antar manusia terhadap kepuasan dalam pelayanan program BPJS Kesehatan di UPTD Puskesmas Astanagarib Kota Cirebon tahun 2014. Hubungan antar manusia merupakan interaksi pemberi pelayanan kesehatan dengan pasien atau konsumen. Hubungan antar manusia yang baik akan menimbulkan kepercayaan dengan cara saling menghargai, menjaga rahasia, saling menghormati, responsif, memberi perhatian, dll.6 Aspek hubungan antar manusia ini penting untuk memberikan pelayanan kesehatan yang bermutu sehingga harapan dan kebutuhan pasien terpenuhi.

Asumsi peneliti mengenai hal tersebut dikarenakan hubungan antar manusia atau interaksi sosial di UPTD Puskesmas Astanagarib Kota Cirebon sudah baik dalam segi menjaga privasi pasien, keramahan petugas dan perlakuan petugas terhadap pasien. 


\section{SIMPULAN}

1. Ada hubungan antara aspek ketepatan waktu terhadap kepuasan pelayanan program BPJS Kesehatan di UPTD Puskesmas Astanagarib Kota Cirebon tahun 2014.

2. Ada hubungan antara aspek informasi terhadap kepuasan pelayanan program BPJS Kesehatan di UPTD Puskesmas Astanagarib Kota Cirebon tahun 2014.

3. Ada hubungan antara aspek kompetensi teknis terhadap kepuasan pelayanan program BPJS Kesehatan di UPTD Puskesmas AstanagaribKota Cirebon tahun 2014.

4. Tidak ada hubungan antara aspek hubungan antar manusia terhadap kepuasan pelayanan program BPJS Kesehatan di UPTD Puskesmas Astanagarib Kota Cirebon tahun 2014.

\section{SARAN}

1. Kepada masyarakat agar lebih secara terbuka mengemukakan kritik yang membangun terhadap fasilitas pelayanan kesehatan milik pemerintah (Puskesmas) sehingga informasi yang dibutuhkan untuk mengukur kepuasan pasien menjadi lebih mudah.

2. Untuk selalu meningkatkan kualitas kinerja kedisiplinan pelayanan kesehatan mengenai jam buka dan waktu tindakan agar pasien lebih merasa puas terhadap pelayanan kesehatan di Puskesmas.

3. Mengadakan pelatihan tentang pengetahuan dan keterampilan mutu dan teknik jaminan mutu pelayanan kesehatan yang diperlukan oleh petugas kesehatan.

4. Mengadakan penyuluhan kembali tentang Jaminan Kesehatan Nasional (JKN) dan Badan Penyelenggara Jaminan Sosial (BPJS) Kesehatan agar para kader dan tokoh masyarakat lebih memahinya.

5. Agar mutu pelayanan lebih meningkat, sebaiknya peraturan yang ada lebih dipertegas lagidengan berlakunya sanksi dan penghargaan agar dapat memberikan motivasi terhadap karyawan.

6. Menyediakan kotak saran guna mengetahui kebututhan dan tuntutan nyata pasien atau konsumen akan pelayanan kesehatan sebagai feed back atas apa yang diberikan oleh petugas kesehatan.

\section{DAFTAR PUSTAKA}

1. Azwar, Azrul. Program Menjaga Mutu Pelayanan Kesehatan. Jakarta: Yayasan Penerbit IDI; 1999.

2. Kemenkes RI. Buku Saku FAQ (Frequently Asked Questons) BPJS Kesehatan; 2014

3. Badan Penyelenggara Jaminan Sosial (BPJS) Kesehatan. Data Peserta BPJS Wilayah III Cirebon: Cirebon; Mei 2014

4. DINKES Kota Cirebon. IKM Pelayanan Puskesmas di Kota Cirebon Tahun 2012: Cirebon; 2012

5. Notoatmodjo, Soekidjo. Metodelogi Penelitian Kesehatan. Jakarta: PT.Rineka Cipta; 2010.

6. Hery. Pelayanan Kesehatan; [diakses tanggal 18 juni 2014]. Diunduh dari: http://herykesehatan.blogspot.com/2011/11/normal-0-false-false-false-en-us-X-none.html 